\title{
Swedish Business Leaders Prospecting Sustainability - Finding the Future with Purpose, Systems Approach, Empathy \& Transformation
}

\author{
Johanna Hallin $^{1}$ \& Nathalie Ahlstedt Mantel ${ }^{1}$ \\ ${ }^{1}$ Inter Business Initiative, Stockholm, Sweden \\ Correspondence: Nathalie Ahlstedt Mantel, Stockholm, Sweden. \\ Received: January 30, 2018 \\ doi:10.11114/bms.v4i1.3058 \\ Accepted: February 19, 2018 \\ Online Published: February 26, 2018 \\ URL: https://doi.org/10.11114/bms.v4i1.3058
}

\begin{abstract}
In this report, we are continuing the discussion on the conclusions from the article "The Inter Business Index: Developing a Tool for Measurement and Comparability of Holistic Sustainability in Businesses" that was published in May 2017 by Hallin et al (2017) and claim that there is need for a new perspective that bring sustainability to a new level - that might be more successful at solving our shared global problems. In an attempt to understand business sustainability and its journey from early day CSR initiatives - towards being a central part of business strategy, we have looked at the structures and strategies companies use to understand sustainability, via reporting and profitable models. To deeper understand the importance of leadership and mindset in regard to sustainability, we have examined how the Inter Business Principles of purpose, empathy, system approach and transformation applies to the sustainability challenges leaders are facing today. Through dialogue with business leaders in Sweden and literature on business sustainability, we have identified leadership and investors as keys for corporate sustainability to take its next step.
\end{abstract}

Keywords: sustainability, business models, leadership, inter business, purpose, empathy, systems approach, transformation

\section{Introducation}

\subsection{Business and Sustainability - A Changing Field}

Sustainability is a broad term and can be defined and understood in many different ways depending on context. Although, the famous and groundbreaking "Brundtland Report" written by Keeble (1988) defined sustainability as a "development that meets the needs of the present without compromising the ability of future generations to meet their own needs"- a wording that has become widely used when describing the field on an overarching level. Sustainability as a concept can be applied to a broad variety of actors, and corporate sustainability is often understood as the "triple bottom line" - people, planet, profit as J. Elkington (1998) described it in 1994. Businesses have immense impact on society, and the three pillars of sustainability - social (people), environmental (planet) and financial sustainability (profit) need to be aligned and measured for businesses to be sustainable.

Sustainability has developed further since the Brundtland Report in 1987 and John Elkington's findings in 1994 and has become a force to be reckoned with for all kinds of stakeholders as they relate to businesses. For example, according to an international survey done by Unilever (2017), consumers worldwide claim sustainability to be an increasingly important factor for them as they are choosing which brands to buy. Political initiative and funding is being laid behind new global governance goals such as the UN Sustainability Agenda 2030 and the major research project Horizon 2020 run by the EU that aims at developing a sustainable world via new research. The European Parliament, Counsil of the European Union (2014) has implemented a new directive, Directive 2014/95/EU, that requires all member states to enforce legislation that requires large companies with more than 500 employees (which is about 6000 companies in the the EU) to report on their sustainability work through their environmental, social, employee-related, human rights, anti-corruption and bribery matters. They must also describe their business model, outcomes and risks, and the diversity strategies in place. They are encouraged to rely on recognized frameworks such as the GRI's Sustainability Reporting Standards (2017). 
The fact that more companies than ever report on their sustainability work describes how the field has moved up the ladder of importance in the corporate, governance and consumer sphere. But as we are to highlight in this report - there are still gaps in the corporate approach to sustainability - an indicator for this can be found in regard to sustainability reporting, especially as a tool for decision-making processes, which we will use as an example.

\subsection{Why Sustainability Is Relevant for Business Leaders}

Sustainability is a growing, developing and becoming a more important field for stakeholders and business leadership alike. The need for new ways to work with, and report on sustainability is important throughout the value chain. Apart from the brand building aspect of sustainable companies that have been central, research show that there are tangible profits to be made from sustainability work as we will discuss below.

Margolis, Elfenbein \& Walsch (2003) coined the famous theory of "doing well by doing good" - that links financial performance to sustainability work in the term of including several stakeholders' apart from shareholders' needs when running a company. This is a belief system that also depends on the opposite - that there are directly negative financial results that come from not working with sustainability that destroy shareholder value - consumer boycotts, strikes, government fines and problems in attracting enough talent to hire, according to Serafeim (2013).

Ameer \& Othman (2011) looked at statistics from 100 global corporations to see if they could find a correlation between an ambitious sustainability agenda and financial performance. Their statistical results prove reasonable evidence that companies that emphasize sustainability have higher financial performances in regard to return on assets, profit before taxation, and cash flow compared to the ones that don't. They also show that the higher financial performance has increased and sustained over several years.

Research done by Schaltegger et al. (2016) also show that many of the pioneers in business sustainability have integrated sustainability in the core of their business models- that is bringing sustainability into their core strategies, which demands championing by business leadership.

To summarize: literature suggests that sustainability matters not only because it is "good" or "right" in the eyes of society - but also because it is profitable and a must have for businesses moving forward in a modern and globalized economy.

\subsection{Reporting on Sustainability in Relation to Corporate Governance}

Even though sustainability reporting has become a way to understand goals, efforts and activities in the corporate sustainability field today - that image provides little information on the bigger, systematic view on sustainability needed in increasingly complex value chains, especially as they often are separated from financial reports. According to Eccles and Serafeim (2014), critics claim that financial reports fail at capturing the true assets of a company in a more knowledge-based era, a gap that could be filled by a sustainability aspect- or reporting. The separation of the reports is in itself a reflection of our understanding of the role of sustainability in the business model - as the financial report is geared towards investors, and the sustainability reports are aimed at other stakeholders, like customers, NGO's, suppliers and the local community.

There is also a difference in regulation between the two - as financial reports are based on laws and accounting frameworks up for external auditing, while sustainability reporting is done internally and voluntarily. Even though the EU recommends reporting after certain standards, as the Global Reporting Initiative, there is no forcing incitement for companies to report on sustainability, and there are no centralized external structures for audits. An interesting example highlighted by Eccles \& Serafeim (2014) is South Africa, where it is mandatory for companies to work with integrated reporting, but where there are no strict guidelines, rules or standards that decides what a company should include in such a report. This shows a hierarchy of reports as tools for companies moving forward - that show that the financial reporting still is seen as more important and central for businesses and the strategic decisions, and sustainability reporting represents a soft value on the side to please external stakeholders.

Still, Ioannou \& Serafeim (2012) show that investors are increasingly interested in sustainability when formed as ESG (environment, social, governance) data. A fact that could be indicating a realization amongst leadership of the importance for sustainability to be brought into strategy and leadership in businesses, but are also driven by ethical and economic considerations from individual investors, as the data could decrease the risk for companies according to UNEPFI (2006).

The investor interest in sustainability reporting highlights the gaps in the financial reports; that they are unable to provide necessary information about a business development as they are lacking the ESG dimension. Still, financial reports have many features missed in sustainability reporting as of now - for example audited information and up to date results. The results are connected to and presented in relationship to the business model and strategy - which is not the case in the traditional sustainability report. This separation of financial and sustainability reports and levels of 
abstraction leave investors ill-equipped to understand how sustainability and ESG is connected to the value creation process of the organization as a whole according to Eccles \& Serafeim, (2014).

An attempt to bring the financial and sustainability reporting efforts closer to one another is Integrated Reporting. In a globalized economy where talent, goods, information and innovation travel swiftly - a company need to be able to navigate in a complex reality with a multitude of stakeholders. Any given company might receive materials from one end of the world, employees might be located at another and end-consumers are somewhere else entirely. This new set up demands new efforts and strategies to work with sustainability in a credible way, resulting in the fact that sustainability is in the process of being developed.

The International Integrated Reporting Council (IIRC) (2017) defines integrated reporting as "An integrated report is a concise communication about how an organization's strategy, governance, performance and prospects, in the context of its external environment, lead to the creation of value in the short, medium and long term". Serafeim (2014) argue that since its pilot in 2013, Integrated Reporting has become more common in the sense that companies have started to include sustainability data into their financial reports, but there is still a limited understanding of the field.

\subsection{Leadership and Corporate Sustainability}

In an article from 1970, Milton Friedman (1970) wrote that the only "social responsibility of businesses is to increase its profits". A quote that has aged poorly into the reality of business today. Research by Heslin \& Ochoa (2008) business leaders are increasingly concerned about how their businesses can prosper from addressing social and environmental challenges. For example, more than 9700 companies from 161 countries has joined the UN Global Compact (2017) initiative promoting sustainability and human rights. A changed mindset within the leaders of the global business community could be portrayed through a quote by David Brower, Executive Director of the Sierra Club as he said: "There is no business to be done on a dead planet" (2008)

As sustainability is developing into being an important subject for corporate governance and investors, the need to understand how these groups relate to sustainability and change grows. Individuals within corporate sustainability has been the objective of extensive research - often by highlighting the importance of personal values, attitudes and beliefs in driving the sustainability managers work forward, for example by Visser \& Crane (2010). But as sustainability is developing into becoming a corporate governance issue - we need to understand the investor and leadership perspective - how they reason, relate to and perceive sustainability in the business model and strategy to understand the reality of corporate sustainability today and its development going forward.

McEwen \& Schmidt (2007) suggests that leadership (in the terms of the function; board, management, executive director etc.) mindset and sustainability efforts are closely aligned. To achieve complex sustainability outcomes, an organization requires advanced leadership capacities and understanding about the field.

According to McEwen \& Schmidt, two understandings can be applied on mindsets on sustainability amongst leaders - "translation" which relates to framing sustainability in terms that others understand where they are now, and "transformation" which refers to the potential for leaders to up-shift their own perspectives and capacities through vertical development.

One could argue that traditional sustainability reporting is aligned with the concept of "translation" - providing an image of specific activities and outcomes achieved in the sustainability field in a given amount of time. The most common, overriding and recurring challenges found in the McEwen and Schmidt research was that of "embedding sustainability" - bringing sustainability in to the core of the business. That is using a new approach to sustainability where it is a key part of the business model - which requires a different, "transformational" mindset amongst leaders.

Literature and research reflects a started movement towards the transformational mindset where business leaders identify the benefits of bringing sustainability to the core strategies and business models, although the tools to some extent are missing. E. Neville Isdell, Chairman and CEO of The Coca-Cola Company reasoned around this journey during the Global Compact Leaders Summit in July 2007:

"Business must become agents of transformation. We have the resources. We have the talents. And let's be clear here, we have the self-interest. Business has stepped up with both promises and programs. But if we add up all the great progress to date, it's only a mildly encouraging start. It's time to scale up. It's time to leverage our efforts through concerted, coordinated, cooperative global action."(2007)

\subsection{The Inter Business Index and Its Principles}

In May 2017 the Inter Business Initiative published the article by Hallin et al (2017) "The Inter Business Index: Developing a Tool for Measurement and Comparability of Holistic Sustainability in Businesses" which introduced the Inter Business Index as a new way to measure and compare sustainability as future preparedness in companies. Using 
publically available materials and interactions, the Inter Business Index measure how well companies work with the components purpose, empathy, systems approach and transformation - moving from traditional sustainability towards future preparedness. By analyzing four key components the Index aim at giving a comparable image of a how well companies understand sustainability as holistic value creation.

\subsubsection{The Principles}

Headlines 1.3.1 to 1.3.4 describing the principles are at large quoted from "The Inter Business Index: Developing a Tool for Measurement and Comparability of Holistic Sustainability in Businesses" (2017) for accuracy.

\section{a. Purpose}

Purpose is what the company is really about, and requires a clear understanding of the operations. Purpose gives companies the opportunity to work with intention and with a shared cause, as written by Schultz (2014). It is central to work with purpose in the core of strategy and operations when applying a holistic approach to sustainability. Hollensby et al., (2014) reserach on purpose acknowledges the interconnection of both business and society, both of which are dependent on, and cannot thrive without, the other.

b. Empathy

Pavlovich \& Krahnke (2012) defines empathy represents the ability to place oneself in the shoes of the stakeholder, allowing us the share the experience of others. Gorry \& Westbrook (2011) argue that empathy helps businesses see matters from the stakeholders' view and helps them understand that ultimately, the goal of bringing solutions and products to the marketplace is to improve people's' lives, not to simply make organizations more profitable or efficient, Chokdee Rutirasiri emphazises in an interview with Hallin et al., (2016).

c. Systems Approach

Businesses are part of society, and, as Rüdiger (2011) writes; responsibility for human development and wellbeing has been increasingly assigned to companies. Barile et al., (2014) claim that for businesses to fully do this, they need to holistically take account of all the different aspects that affect and interact with each other, and consider the whole system that they are a part of). That is - according to Arnold \& Wade (2015) to move away from a linear thinking and instead adopt a system approach to better understand and predict possible outcomes of their decisions.

\section{d. Transformation}

The field of business transformation is about making changes to meet new circumstances and external factors like new markets, challenges and demands. Companies today exist in a global context with a highly present technological transformation occurring. Pahurkar 2014) writes that businesses affect and are affected by more factors than they did just acting on local and regional markets, making it imperative to adapt and innovate to be able to stay competitive and even survive. This makes it impossible for businesses to main a status quo, and the skills of transformation are necessary in navigating ways forward, and forging new ones.

\subsubsection{Relevant Conclusions From the Inter Business Article}

The article written by Hallin et al., (2017) highlights a gap in how companies fail at navigating amongst the existing knowledge base, and applying it to their own core business. Sustainability reporting as formed today lacks the necessary holistic approach that gives the information needed to the corporate leadership - since it is focused on the context specific aspects. The Inter Business Index article claim that there is need for a new perspective that bring sustainability to a new level - that might be more successful at solving our shared global problems.

\section{Method}

The Inter Business Framework is a way of analyzing companies and their future preparedness through the four principles of purpose, empathy, systems approach and transformation. The journey that corporate sustainability is currently on - moving towards a more complex structure where a lot is still to be invented; requires strong leadership with the ability to deal with a variety of stakeholders, jurisdictions and contexts. Via interviews with a selected group of Swedish business leaders we are examining how the Inter Business Principles apply to the challenges leadership is facing today in regard to sustainability work, and relate to possible solutions and next steps. The data is clustered in relation to the questions asked during interviews.

Based on literature studies and the earlier research done to present the Inter Business Index, we are examining how business leadership are relating to the updated topics and complexities that are forming corporate sustainability today via qualitative interviews with business leaders in Sweden. We have conducted 14 dialogues with leadership from eight Swedish companies during the fall and winter of 2017 in Stockholm, Sweden. The interviewed business leaders represent the following companies: 


\author{
AMF \\ BillerudKorsnäs \\ Frösunda Omsorg \\ $\mathrm{H} \& \mathrm{M}$ \\ Husqvarna \\ Lantmännen \\ Philips \\ Stora Enso
}

We have purposely chosen companies from a wide range of areas - fashion, care, health, pensions, forestry and foods with the shared features of being medium sized to large companies operating in Sweden. Depending on their business area, they have different starting point when working with stakeholders and sustainability. They present a mix of business models - "business to business" as well as "business to consumer" - and face different challenges when navigating the future of sustainable business models.

The purpose of this paper is to explore the discourse used around topics related to business strategy and sustainability by business leaders in Sweden. We structured the interviews around the question:

- How does business models and value creation relate to the concept sustainability in your leadership and company?

\title{
2.1 Material
}

The research material is built on the Inter Business Index research conductued by Hallin et al., (2017) published in May 2017 and have drawn up the topic around which the interviews with leaders from medium and large companies in Sweden have revolved.

\section{Results}

We have clustered the outcomes of the dialogues around recurring topics and insights provided by the respondents in an effort to highlight the major challenges for companies in relationship to the future of sustainability. We attempt to focus on themes and clusters that we found in interviews, without focusing on specific quotes surrounding strategy, priorities and circumstances unique to the companies interviewed as that information could be sensitive to reveal in this context. We have clustered the findings in the interviews around the three following topics:

Business models and value creation in regard to sustainability

Adding empathy to a systematic perspective

Investor views on purpose, values and sustainability

\subsection{Business Models and Value Creation in Regard to Sustainability}

Several of the companies emphasized the importance of moving beyond the specific issues and topics relating to sustainability - and bring a holistic view that feeds into their business model. The leaders are not insecure about the field or its importance in the future of business - but need tools to understand how to use sustainability and the information to be found, in a way that provides clear connections to the company's purpose, goals and strategy. Some companies have started the process to tie their sustainability goals to their overall business goals, but leaders are challenged to fully understand the process and value of what that means in the practical.

As some of the business leaders work at companies that have been around for hundreds of years, the need for transformation is even greater. When the physical factory and engineering outputs has been at the core of a company many questions rise in regard to value creation, business models and sustainability. Both as new demands are being placed on products, but also as sustainability aspects provides questions like: should we be product-driven in the future?

A few of them have arrived at a point where they discuss value creation as a whole in regard to sustainability, that is: when they run a profitable business, have a sustainable production and product and a sustainable relationship with the world. That last leg is often the youngest and most undeveloped, and something they are working at integrating into the business model. The big questions are present; what is a company supposed to be in the future and in future societies? How do you place value on what lies beyond the owner/customer relationships? That is - the whole impact and value creation of the operation.

The relation that business models have to Agenda 2030 is especially interesting, as many leaders is confronted with the need to investigate further how a sustainable business model could work for their company. Companies is a vital part of 
lifting and fulfilling the Agenda 2030, and the need to provide structures to do so is equally important. For the business leaders interviewed, this theme is top of mind when thinking about sustainability in relation to their company.

\subsection{Adding Empathy to a Systems Perspective}

The systems perspective is not that developed or implemented in these organizations, but the knowledge about it is extensive and the tools are many. What we can see through our dialogues is an indication of a newfound interest of the information that can be found in the interpersonal relationships - and adding empathy as a way to understand that field.

Some companies have developed their financial reporting by adding stakeholder groups in relation to each financial performance in the highest level of financial reporting. For example, consumers are related to revenue, distributors to purchases and the result to owners as a stakeholder group. In this way, they aim at more closely connect the financial sustainability with the stakeholders connected to it. To show that the financial results are very much dependent on the stakeholder groups affected, and not simply a value to consider on its own.

Another example is the ambition to move from transactions to relationships, which is a transformational journey aimed at creating value in the interpersonal and in the company's interactions. That is, moving from what the company is doing now - onto meeting needs and solving problems for their stakeholders on a long-term basis.

The "business to business"-segment is at large challenged by the interaction with stakeholders outside of their own company. Interpersonal information is a new and intriguing aspect for them to explore. On the other hand, the companies working close to their end-user is exploring empathy as a business development tool and has an easier time understanding the concept in regard to their own operation. To understand consumers' individual needs, the consumer as a group and their relationship to the company is key to developing the concepts required to meet needs and support stakeholders. To give consumers access to feedback tools to make their voices heard is a process to be encouraged, especially according to those who work with weak target groups without influence or power in society.

Some have extended their work to measure consumer happiness with products and applied it to distributors and investors as stakeholder groups as well, as a way to look more closely at the value that they create.

\subsection{Investor Views on Value, Purpose and Sustainability}

Business leader have noticed a shift within focus areas of boards, owners and investors. They are moving from asking about specific questions such as numbers on carbon dioxide emissions per year, "proof" for future operations - that is what and how the operations will commence, towards questions of purpose, values and implementation. The investors are not as interested in the specifics as before - but more so to create conditions and competencies within the organization that can solve the challenges that lies ahead. They are more interested in capturing learnings as to how to create consensus in framing challenges or changing company culture.

Working with values as a tool for value creation have become an important issue in some companies understanding of sustainability at the governance level of the organization. As financial performance still is the most important part of the triple bottom line, there need to be a consensus amongst investors when discussing and working with the other two. Business leaders notice a that some investors understand sustainability as the opposite of profitability - a view that is enhanced when leaders in the organization lack tools to link sustainability goals to business goals and sustainability reports to financial reports.

\section{Conclusions}

Several of the business leaders interviewed have followed the field of sustainability and the journey it has taken over the course of the past years. They are also working at companies that has ambitious sustainability agendas - which gives them an interesting vantage point of leading their organizations towards an ambitious goal, without a map to guide them. Sustainability as a concept is developing further, the limits are being pushed and the definition of what a company is, or should be, are being re-forged in the minds of business leadership.

Sustainability has become a question of competition in Sweden, and companies are struggling to understand how to innovate and adapt to make sure that they are coming out strong on future markets where sustainability will mean more that it has before as a success factor.

Our research show that new stakeholder groups are taking part in shaping corporate sustainability. Investors and CEOs are stepping up to be main drivers for change, which is a relativly new development. The shift from a matter of communication to a matter of strategy is clear in our interviews. And even though the movement of corporate sustainability is rapid yet unclear, new elements are being added to the term according to our respondents. Values and ethics are new themes that are gaining ground in the corporate governance sphere when relating to sustainability - and discussions around them in relation to profitability is evident and pressing. There seems to be a generational shift in the investor and leadership segment, not necessarily in age - but in attitudes to the relationship inbetween the three 
components of the triple bottom line. Even though research show that sustainable companies are more financialy profitable, it seems to be a difficult hurdle to pass, changing the mindset of more traditional investors and leadership members.

But as well as new stakeholder groups, our interviews shine a light on new topics that are being discussed under the sustainability umbrella. Values as a mean to resolve conflicts, empathy as a tool to get to know your stakeholders and business development with forsight in pursuit of a sustainable world.

Sustainability is moving from the sustainability department to the Board room, and business leaders need to understand how to harness the potential that this new layer of business bring to the table. The theories are many and ambitions are high, but the future is unclear. The common realization amongst the business leaders interviewed is that companies of all sizes and segments has to work hard to understand, adapt and develop their business models, relationships and governance to survive in a rapidly changing future.

\section{Discussion}

Our research shines light on the uncertain future of corporate sustainability work - and how the people working with the field are inventing the path as they go. There are no certain models that determine success. Experimentiality seems to be wide spread, and the search for answers are cutting through academia, business and practitioners alike. The uncertainity of the field seems to be partly rooted in the uncertainty of what a company is in our time and context, and how they should be navigating markets, challenges and commitments to stakeholders throughout the value chain.

The question of incentive becomes clear - are businesses to act sustainable at their own will, or should there be forcing incentive in regard to the Agenda 2030 goals? Initiatives as the Global Compact engages thousands of companies, but are based on the CEO's commitment to take steps towards the UN sustainability goals. The structure of such a commitmemt makes it difficult to follow up change or demand any kind of systematic approach to rebuilding business models to make them more sustainable.

Forcing incentives in turn are colliding with free market logic in the sense of restraining profitable models in favour of environment and people. That route would demand top-down regulations on reporing, business models and outputs, and would probably restrain the innovation and development well needed to solve the challenges ahead.

Business leadership are actively searching for answers regarding the future of sustainability in their context, and these known un-knowns are proving to be an ever more important point on the corporate agenda.

The topic of corporate sustaianbility demand more research conducted close to businesses and business leaders. Findings must be incorporated in education and policy making on a broad scale if the promising potential in corporate sustainability work is to be successful at work to solve our pressing global challenges.

\section{Acknowledgements}

This paper continues the work published on the Inter Business Index in The Journal of Management \& Sustainability in 2017, and on the pilot research published in 2016 in European Public \& Social Innovation Review. Important contributors to mention in bringing about the Inter Business framework is Evelina Fredriksson, Rebecca Altman, Shimeng Zhou \& Michelle Sandberg.

\section{References}

Ameer, R., \& Othman, R. (2012). Sustainability Practices and Corporate Financial Performance: A Study Based on the Top Global Corporations (October 15, 2012). J. Bus Ethics (2012), 108, 61-79.

Arnold, R. D., \& Wade, J. P. (2015). A Definition of Systems Thinking: A Systems Approach. Procedia Computer Science, 44, 669-678. https://doi.org/10.1016/j.procs.2015.03.050

Badman, D. Director Sustainability and Public Affairs, Billerud, K. (2017, November 25). Personal interview.

Barile, S., Saviano, M., Landolo, F., \& Calabrese, M. (2014). The Viable Systems Approach and its Contribution to the Analysis of Sustainable Business Behaviors. Systems Research and Behavioral Science, 31(6), 683-695. https://doi.org/10.1002/sres.2318

Blom, L. B. (2017, October 23). Personal interview.

Eccles, R. G., \& Serafeim, G. (2014) Corporate and Integrated Reporting: A Functional Perspective. Chapter in Stewardship of the Future, edited by Ed Lawler, Sue Mohrman, and James O'Toole. Greenleaf, 2015, https://doi.org/10.2139/ssrn.2388716

Elikington, J. (1998). Accounting for the triple bottom line, Measuring Business Excellence, 2(3), 18-22. https://doi.org/10.1108/eb025539 
Faye, L. (2017, October 11). Personal interview.

Friedman, M. (1970). The social responsibility of business is to increase its profits. New York Times Magazine, 32, 122-126.

Gorry, G. A., \& Westbrook, R. A. (2011). Once More, With Feeling: Empathy and Technology in Customer Care. Business Horizons, 54(2), 125-134. https://doi.org/10.1016/j.bushor.2010.10.003

GRI \& CSR Europe. (2017, December 14). Member State Implementation of Directive 2014/95/EU - A comprehensive overview of how members states are implementing the EU Directive on Non - Financial and Diversity Information. Retrived from: https://www.globalreporting.org/resourcelibrary/NFRpublication\%20online_version.pdf

Hallin, J., Fredriksson, E., Altman, R., \& Zhou, S. (2016). Developing a Human Centered Business Index—Leading with Purpose, Empathy, Systems-Approach and Resilience in "Business Beyond Sustainability". European Public \& Social Innovation Review, 1(1), 33-43.

Hallin, J., Sandberg, M., \& Ahlstedt, M. N. (2017). The Inter Business Index: Developing a Tool for Measurement and Comparability of Holistic Sustainability in Businesses. Journal of Management and Sustainability, 7(2), 2017. https://doi.org/10.5539/jms.v7n2p27

Heslin, P. A., \& Ochoa, J. D. (2008). Understanding and Developing Strategic Corporate Social Responsibility. Organizational Dynamics, 37, 125-144, 2008. https://doi.org/10.1016/j.orgdyn.2008.02.002

Hollensbe, E., Wookey, C., Hickey, L., George, G., \& Nichols, C. V. (2014). Organizations with purpose. 40 Academy of Management Journal, 57(5), 1227-1234. https://doi.org/10.5465/amj.2014.4005

Integrated Reporting Counsil. (2017, December 14). What? A tool for better reporting. Retrived from: https://integratedreporting.org/what-the-tool-for-better-reporting/

Ioannou, I., \& Serafeim, G. (2012). What Drives Corporate Social Performance? The Role of Nation-level Institutions. Journal of International Business Studies, 43(9), 834-864. https://doi.org/10.1057/jibs.2012.26

Jaillot, T. Vice President, Husqvarna. (2017, October 27). Personal interview.

Johansson, C. Sustainability Director, Lantmännen. (2017, October 23). Personal interview.

Keeble, R. B. (1988). The Brundtland report: 'Our common future'. MBBS MRCGP Medicine and War, 4(1). https://doi.org/10.1080/07488008808408783

Larsson, $\AA$, Global Media and Sustainability Manager, Husqvarna. (2017, October 27). Personal interview.

Larsson, E. Sustainability Business Development and Controlling Manager, H\&M. (2017, December 7). Personal interview.

Lilja, U. Communications Director, Stora Enso. (2017, October 27). Personal interview.

Lorentzon, M. Sustainability Business Expert, H\&M. (2017, December 7). Personal interview.

Lyrvall, P. CEO, Stora Enso. (2017, October 27). Personal interview.

Margolis, J., Elfenbein, H. A., \& Walsh, J. P. (2013). Does It Pay To Be Good? A Meta-Analysis and Redirection of Research on the Relationship between Corporate Social and Financial Performance. HBS Working Paper.

McEwen, C. A., \& Schmidt, J. D. (2007). Leadership and the Corporate Sustainability Challenge: Mindsets in Action. http://dx.doi.org/10.2139/ssrn.1118071sid36

Nyström, S. Sustainable Business Expert - Human Rights, H\&M. (2017, December 7). Personal interview.

Pahurkar, R. N. (2014). The Comprehensive Approach for Creativity and Innovation-Enhancement and Sustainability in Social Enterprises. Journal of Management and Sustainability, 4(2). https://doi.org/10.5539/jms.v4n2p111

Pavlovich, K., \& Krahnke, K. (2012). Empathy, Connectedness and Organisation. Journal of Business Ethics, 105(1), 131-137. https://doi.org/10.1007/s10551-011-0961-3

Rosencrantz, C. Quality Director, Frösunda Omsorg. (2017, November 1). Personal interview.

Rüdiger, H. (2011). Integrating Corporate Responsibility and Sustainable Development-A Normative- Conceptual Approach to Holistic Management Thinking. Journal of Global Responsibility, 2(1), 8-22. https://doi.org/10.1108/20412561111128492

Schaltegger, S., Lüdeke, F. F., \& Hansen, E. G. (2016). Business Models for Sustainability—A Co-Evolutionary Analysis of Sustainable Entrepreneurship, Innovation, and Transformation. Organization \& Environment, 29(3), 264-289. https://doi.org/10.1177/1086026616633272 
Schultz, R. J. (2014). Framing the Organization's Purpose with Its Ultimate Goals in Mind. Global Business and Organizational Excellence, 33(3), 46-55. https://doi.org/10.1002/joe.21543

Serafeim, G. (2013). The Role of the Corporation in Society: An Alternative View and Opportunities for Future Research. https://ssrn.com/abstract=2270579

Serafeim, G. (2014). Integrated Reporting and Investor Clientele. Journal of Applied Corporate Finance, 27(2). Spring 2015. https://doi.org/10.2139/ssrn.2378899

The European Parliament, Counsil of the European Union. (2014) Directive 2014/95/EU, Official Journal of the European Union, 15.11.2014.

Tiblad Berntsson, C. Social Sustainability Manager, H\&M. (2017, December 7). Personal interview.

UN Global Compact. (2017, December 14). What is Global Compact? Retrived from https://www.unglobalcompact.org/what-is-gc

UNEPFI. (2006). Show me the Money: Linking Environmental, Social and Governance Issues to Company Value.

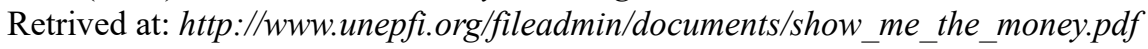

Unilever Global Company Website. (2017, May 1). Report shows a third of consumers prefer sustainable brands, Retrived https://www.unilever.com/news/press-releases/2017/report-shows-a-third-of-consumers-prefer-sustainable-brands. html

Viefhues, A, Sustainability Manager, AMF. (2017, October 11). Personal interview.

Visser, W., \& Crane. (2010) Corporate Sustainability and the Individual: Understanding What Drives Sustainability Professionals as Change Agents. http://dx.doi.org/10.2139/ssrn.

\section{Copyrights}

Copyright for this article is retained by the author(s), with first publication rights granted to the journal.

This is an open-access article distributed under the terms and conditions of the Creative Commons Attribution license which permits unrestricted use, distribution, and reproduction in any medium, provided the original work is properly cited. 